\title{
Promoting positive mental health among students in Malaysia
}

\author{
Che Rozaniza Azizan ${ }^{1}$, Asbah Razali ${ }^{2}$, Rajalingam Pillai ${ }^{3}$ \\ ${ }^{1}$ Dept. of Foundations of Education (Educational Psychology), Faculty of Educational Studies, University of Putra Malaysia, Selangor \\ ${ }^{2}$ Dept. of Human Development and Family Studies, Faculty of Human Ecology, University of Putra Malaysia, Selangor \\ 3School of Language Studies and Linguistics, Faculty of Social Sciences and Humanities, National University of Malaysia, Bangi, \\ Selangor
}

\section{Email address:}

rozaniza.azizan@gmail.com(C. R. Azizan), asbahrazali@um.edu.my(A. Razali), rajalingam_pillai70@yahoo.com(Pillai R.)

\section{To cite this article:}

Che Rozaniza Azizan, Asbah Razali, Rajalingam Pillai. Promoting Positive Mental Health among Students in Malaysia. Psychology and Behavioral Sciences. Vol. 2, No. 2, 2013, pp. 73-82. doi: 10.11648/j.pbs.20130202.18

\begin{abstract}
This article examines analytic issues in research on mental health affecting the students in Malaysia. The review notes the continued move in briefing on the definition of mental health and mental health manner in promoting healthy secondary school students in Malaysia. At the point, parents and teachers are the individuals identified to perform this heavy duty and their collaboration is vital in promoting positive mental health among the students. Thus, the discussion will include definition of mental health, types of mental illness and appropriate measures taken to promote mental health, particularly among students in Malaysia.
\end{abstract}

Keywords: Mental Health, Students, Malaysia, Mental Illness, Promote Mental Health

\section{Introduction}

The number of cases related to mental health problems among students are increasing every year (Zivin, Eisenberg, Gollust \& Golberstein, 2009). According to the World Health Organization (WHO) report, mental health issues are expected to increase by $15 \%$ by 2020 and young people are the group most at risk of experiencing this problem. Mental health issues are often debated and discussed, whether at the national or global. It is important to give attention to adolescents who experience mental health problems and thus able to eliminate the social stigma of mental illness. Mental health issues are not only associated with mental illness. Mental health is something we all need. It is a feeling of well-being, happiness, the ability to cope with life's challenges, to accept others and most of all, to have a positive attitude towards oneself (Malaysian Mental Health Association, 2008).

In general, we can say that mental health includes the feeling about ourselves, how we feel about the other people and how to handle the demands of life (MMHA, 2008). Thus, based on the definition discussed above, this article will focus more on the understanding of mental illnesses and ways to promote positive mental health by referring to mental illness as the example. According to MMHA (2008), mental illness may affect anyone at any age level and may significantly impair person's ability to form daily activities. Thus, it is necessary to get a clear picture of types of the disease and gain awareness about issues related to unhealthy mental health.

WHO (2012) estimated that around 450 million people suffer from mental illness with one in four families have at least one member with a mental illness at any point in time. According to MMHA (2008), mental illness is often misunderstood. For centuries, it has been seen as either possession by evil spirits, a moral weakness or punishment from a higher being. Those suffering from mental illness are commonly perceived to be restless, violent and unpredictable. There are many forms of mental illness that differ in severity, duration and degree. It is a disturbance of the mind which can affect thinking, feeling and behavior that may interfere with normal functioning, and thus make daily life difficult. Most mental illness can be treated so that a reasonable state of health can be enjoyed. Like physical illness, mental illness is nothing to be ashamed of (MMHA, 2008). Early diagnosis and treatment by expert is needed to regain full functioning of mentally healthy wellbeing.

Depression-a form of mental illness, affects more than 350 million people of all ages, in all communities, and is a 
significant contributor to the global burden of disease (WHO, 2012). In fact the 2012 World Mental Health Day's Theme is also related to mental illness that is Depression: A Global Crisis. World Mental Health Day 2012 aims to encourage governments and civil society around the world to address depression as a widespread illness that affects individuals, their families and their peers, and to recognize that it is a treatable condition (Wan, 2012). According to Deborah Wan, the President of the World Federation of Mental Health (2012), many countries have adopted the World Mental Health Day as a way of promoting mental health since it was introduced in the year 1992.

Specific disorders among students in higher education will also be discussed briefly by referring to a report done by Royal College of Psychiatrists (2011) and a few studies conducted under Malaysian Universities, NGOs and government agencies such as National Anti Drugs Agency. Mental health issues involving adolescents especially those aged 15 and below are now showing a worsening trend. The government is concerned about this issue mainly because this group of adolescents and children are the national assets, their mental health problem may somewhat affect the national development if they are left unrecognized and untreated. This article is hope to provide a deeper understanding on mental health even though there is no line that neatly divides the mentally healthy from the unhealthy as there are many degrees of mental health. This is because no single characteristics can be taken as evidence of good mental health and nobody has all the traits of good mental health all the time (MMHA, 2008).

\section{What is Mental Health}

It is important to clearly understand the meaning of WHO's mental health definition. According to WHO (2012), mental health refers to a broad array of activities directly or indirectly related to the mental well-being component included in the WHO's definition of health: "A state of complete physical, mental and social well-being, and not merely the absence of disease". Thus, we can say that mental health is related to the promotion of well-being, the prevention of mental disorders, and the treatment and rehabilitation of people affected by mental disorders.

According to Skalski and Smith (2006) mental health, like physical health, mental health may be viewed as existing on a continuum from healthy living to chronic illness. In 2001, the U.S. Surgeon General defined mental health as "the successful performance of mental function, resulting in productive activities, fulfilling relationships with other people, and the ability to adapt to change and to cope with adversity" (U.S. Department of Health and Human Services, 2001). A person with positive mental health uses interpersonal assets and skills to function successfully in his or her daily life. Mental health problems emerge when these assets and skills begin to deteriorate, resulting in a struggle to cope with life's challenges and responsibilities. The continued deterioration of these skills signals the onset of mental illness as significant distortions to thinking, coping, and responding dominate personal functioning and impair a person's ability to perform the activities of daily life. All people fall somewhere on this continuum on any given day (Skalski and Smith, 2006).

\subsection{What is Positive Mental Health}

Since the definition of mental health is wide and covers many kinds of mental illness (as well as any other physical or social illness, which are not discussed in this article), it is important that by now we should be able to note that any kind of illness or activities that impedes our functions as a healthy well being would be viewed under a large term, that is mental health. In other words, mental health not only concerns about mental illness alone even though through reading and literature reviews we might be getting the similar message that it is similar to mental illness and its treatment. Concerning mental health, Maharjan (2010) a Psychosocial Field Officer in International Committee of the Red Cross (ICRC), Nepal added that people mostly talk about problems and treatment or prevention but there is little space for those who wish to promote mental health. He urged the understanding of mental health in terms of ways to promote positive mental health, positive emotions, experiences and what the research findings say. His view about positive mental health is based on Marie Jahoda's (1958) Current Concept of Positive Mental Health and also Positive Health Theory from Seligman (2008).

Marie Johada (1958) was the first person who introduced the term positive health by saying that the term mental health is vague, elusive and ambiguous which means many things to many people is considered as bad enough. She argues that positive mental health can be viewed as an enduring personality characteristic or as a less permanent function of personality and the social situation (Jahoda, 1958 in Cardwell and Flanagan, 2005). In her classic book, Current Concepts of Positive Mental Health (1958), Jahoda identified the following six approaches to the definition of positive mental health, which are described in detail below: (1) attitude toward own self; (2) growth, development, and self-actualization; (3) integration; (4) autonomy; (5) perception of reality; and (6) environmental mastery (as cited in Cardwell and Flanagan, 2005). She addressed that acceptance of self, self-confidence, and self-reliance characterize the mentally healthy person. She also added that an important attribute of positive mental health includes the understanding of one's strengths and weaknesses, coupled with the conviction that one's positive characteristics outweigh the negative traits. Independence, initiative, and self-esteem are other indictors of positive mental health (Cardwell and Flanagan, 2005).

According to Seligman (2008), mental health is the overriding theme to emerge from a decade of positive psychology research (consisting of positive emotion, engagement, purpose, positive relationships, and positive accomplishments) is something over and above the absence of mental illness, and it is quantifiable and predictive. It 
predicts lack of depression, higher achievement, and better positive physical health. Thus, promoting positive mental health is an important step towards preventing mental illness and growing resilience (Sujen Man, 2010).

\section{Problem Statement}

Mental health is now a serious issue in the country by referring to articles that are being published in the media. Poor mental health and low perception of well-being may lead to burdensome physiological symptoms. This means, positive perception of psychological well-being contributes to fewer physical problems (Stevenson, 2006). Most of the articles discuss the increasing trend of mental health problems among Malaysians with more people believed to be experiencing some sorts of emotional stress and mental distress. In the last three years, only 1.2 to 1.5 per cent of individuals with mental health issues sought treatment at the public hospitals, which is a cause for concern given the probability that one out of every five Malaysians suffers some form of mental illness.

According to the 2011 National Health and Morbidity Survey, $12 \%$ of Malaysians aged between 18 and 60 are suffering from some forms of mental illness. Of the percentage affected by mental illness, depression made up $2 \%$, psychosis $1 \%$, worrying $1.8 \%$, while the rest involved anxiety disorder, which is a chronic disease, and mild mental diseases. The recent death of a mentally challenged man in Putrajaya has refocused attention on the lack of seriousness with which mental health disorders that are treated in the country (Sinchew, 2012, August 9). The man is said to have schizophrenia. Mental health issue is raising the public concern with the incidence of homicides and suicides among those of mentally-ill persons. This statement is supported by detained of a 44-year-old man who is said to be mentally unstable in the brutal murder of his elderly uncle and aunt (The Star, 2012, Jun 22). This is just an example of murder which is allegedly done by mentally - ill person, but in reality many other cases have found to be related or done by those of the mentally ill persons or psychopaths.

Tragedies involving people with mental health issues are not new to Malaysia, but society has remained apathetic towards the problem (MySinchew, 2012, August 9). Tan Sri Lee Lam Thye, a member of Mental Health Council stated that two separate tragic suicide incidents, one in Malacca and the other in Selangor, highlight the crucial need to do more to promote good mental health in the country. He added that in Malaysia, the suicide rate has increased to between nine and 12 persons per 100,000 population from eight in the 1980s (The Star, 2011, February 11).

Rising stress levels whether in school, at the workplace or elsewhere is one of the factors identified to have association with mental health and could seriously affect one's daily life. Datuk Seri Liow Tiong Lai stated that The Health Ministry views seriously the worsening trend concerning mental health issues involving adolescents and children aged 15 and below by referring to statistics showed mental health problems involving the group rose to 13 percent in $1996,19.4$ percent in 2006 and 20 percent in 2011 (The Star, 2012, October 7). He drew attention to the fact that teens and children today are heavily influenced by the Internet and communications technology to the point it is leading to less parent-child interaction while parents are busy with their careers and also treating lightly the supportive role they need to play when it comes to their children.

In order to promote positive mental health, public awareness serves as one of the great concern addressed by the ministry. Records with the National Mental Health Registry (NMHR) have shown that public awareness about mental health issues is far from satisfactory. Thus, government via Ministry of Health and Ministry of Education should take necessary action to identify those facing problems like stress and depression, and to help the students before the problems worsened and led to severe consequences. It is not denying that NGOS such as Malaysian Mental Health Association has done a tremendous job by providing a dynamic advocate for positive issues towards mental health issues as well as serving as a recognized center for referral and rehabilitation.

It is important to note that mentally healthy people trust others and enjoy being part of a group as well as being on their own. For them, life is meaningful. The background of the article will focus more on the Malaysian context by referring to actions done by the Malaysian Mental Health Association (MMHA) in order to promote mental wellness, with a view of minimizing or eliminating social stigma association with mental illness. But does that mean mental health is only associated with mental illnesses and not the absences of the other diseases? The answer is certainly no because in recent years, mental health services have been encouraged to focus on the needs of patients with more severe mental illnesses (Royal College of Psychiatrists, 2011). Mental health problems, especially stress-related, among Malaysians, including school children are a matter of serious concern and need to be addressed urgently so that mental disorders such as psychosis, depression and suicides can be minimized.

\section{Objective}

The objective of this study is to explore the various aspects of mental health problems among students according to the literature. It will include the students' mental health problems, specific disorders, schizophrenia, depression, manic disorder, anxiety, bipolar disorder, eating disorders, autism-spectrum disorders, alcohol and drug misuse.

\section{Methodology}

This is a library research. Library research concludes the research from conventional sources such as online journal, 
articles and databases. The researchers will gather previous researches from the library, newspapers, internet and databases that are related to this paper. The previous researches are identified in relevant sources using the key words that related to the title of this paper in various search engines and databases. The literatures are gathered and analyzed according to the aspects that fit the paper's title.

\section{Findings}

From the literature, there are a lot of researches about mental health problem among students and young people. There are various types of mental illness. The symptoms are milder with regard to distress and disability but these may still have a deleterious impact on a students' ability to complete their coursework on time or to revise effectively for their examinations (Royal College of Psychiatrists, 2011). What matters is how they manage their emotional stress whether by practicing or promoting positive mental health or continuing with their mental problems without seeking help. Discussion is based on various types of mental illness which can be distinguished by their symptoms or specific disorders (MMHA, 2008 \& Royal College of Psychiatrists, 2011). Some of the more usual types are:

\subsection{Schizophrenia}

Patients suffering from schizophrenia may commit the most heinous crimes as they are disconnected from reality and there is nothing to stop them but turn out to be less dangerous with early treatment (Sinchew, 2012, August 9). Schizophrenia is a major mental illness found across the world with an approximate lifetime risk of between 0.7 and $1.3 \%$ of the population (Royal College of Psychiatrist, 2011).

The annual incidence of schizophrenia is approximately 1 in 10 000. The peak age at onset is between late adolescence and early adulthood and as such students may represent a high-risk group. But MMHA (2008) reported that a schizophrenia episode occurs at any age, although people in the 16-33 age group tend to be most at risk (MMHA, 2008). Genetic inheritance, childhood experience, personality type and biochemical abnormality have been cited as possible factors. Some of the symptoms include fear, withdrawal, mood fluctuations, loss of energy and self neglect.

Royal College of Psychiatrists (2011) stated that low social class and professional achievement may be associated with schizophrenia and thus it may occur less frequently in a student population. Indeed, many people who are diagnosed with schizophrenia may be unable to commence or complete a university course. In a survey of approximately 14600 students registered with the Leeds Student Medical Practice, only two were recorded as having a diagnosis of schizophrenia (Mahmood, personal communication, 2002, quoted in Royal College of Psychiatrists, 2011).

\subsection{Depression}

Depression is a common, serious and complex illness that affects an estimated 121 million people worldwide (MMHA, 2008). Findings from an international survey conducted in early 2005 on behalf of the World Federation for Mental Health (WFMH) revealed substantial gaps in patients' and physicians' knowledge about depression, leading to misdiagnosis or delayed diagnosis.3 For example, individuals suffering from depression, on average, waited more than 11 months to see a doctor and were only diagnosed with depression after five visits to the doctor, further delaying treatment and recovery (as cited in MMHA, 2008).

According to MMHA (2008), depressive disorders occur among all ages, races, and cultures. Some causes of depression include: family environment, life events, biological factors, serious loss or stress - i.e. a divorce, death of a loved one, retirement. People suffering from depression experience both physical and emotional symptoms, including excessive fatigue, disturbed sleep, appetite and weight loss, difficulty in concentrating, a failing memory and diminishing sexual interest.

Depression often comes with symptoms of anxiety (World Federation of Mental Health, 2012). The estimated prevalence of any depressive or anxiety disorder was $15.6 \%$ for undergraduates and $13.0 \%$ for graduate students in an internet-based survey in the USA (Eisenberg et al., 2007). A study in Lebanon found that the prevalence of depression in medical students was as high as 28\% (Mehanna \& Richa, 2006).

These problems can become chronic or recurrent and lead to substantial impairments in an individual's ability to take care of his or her everyday responsibilities. At its worst, depression can lead to suicide. Almost 1 million lives are lost yearly due to suicide, which translates to 3000 suicide deaths every day. For every person who completes a suicide, 20 or more may attempt to end his or her life (WHO, 2012).

\subsection{Manic Disorder}

Manic disorder is characterized by extreme and unpredictable mood changes in the sufferers. The cause is unknown but studies have shown that it could be inherited. Stress may be another cause, for e.g. finding a new job or death of a relative. In student's context, meeting deadlines for assignments and presentation might be the main contributing factors of stress related manic depression. These symptoms include: talkativeness, big spending, risktaking behaviour and sleeplessness, alternating with symptoms of depression (MMHA, 2008).

In the study by Andrews \& Wilding (2004), financial difficulties have made a significant independent contribution to depression that may in turn affect academic performances. Depression and financial difficulties in the middle of the second year predicted a decrease in exam performance from the first to second year. In Malaysian 
context, a study by Zaid, Chan, and Ho (2007) on emotional disorders among medical students in one of the Malaysian private colleges have found out that students who experienced depression had a lower academic performance.

\subsection{Anxiety}

Anxiety is one of the more common reactions to mental stress (MMHA, 2008). $10 \%$ to $15 \%$ of people are affected by some form of anxiety disorder. Long term problems like living in a crowded house can be stressful and even happy events - getting married or switching to new jobs - can cause anxiety. Anxious people feel tense most of the time, having problems with sleeping, are dry in the mouth and are unable to relax.

Anxiety could affect students' academic achievement in the sense that students with high anxiety level perform poorer compared to those with low anxiety (Md Aris Safree and Mariam Adawiah, 2011). Financial and other difficulties seem to increase British students' levels of anxiety and depression (Andrews \& Wilding, 2004). They also found that $40 \%$ of a cohort of University College, London students had attended the student health clinic for psychological problems, characterised by anxiety, tension and poor concentration. Another longitudinal study on anxiety revealed that highly-anxious students, compared to their less-anxious peers, scored significantly lower on measures of academic achievement, aggression, and peer acceptance (Seligmen and Wuyek, 2007).

\subsection{Bipolar Disorder}

According to Royal College of Psychiatrists (2011), bipolar disorder usually begins in adolescence or early adulthood (commonly with an episode of depression) but the correct diagnosis is often delayed for up to 10 years. Recent epidemiological data suggest that exceptional intellectual ability (e.g: the gifted students) may be associated with bipolar disorder, placing the student population at high risk of developing this illness. This statement is rather true as in the death of a Malaysian Chinese Gifted Boy has found to be related to depressions and withdrawal symptoms (The Star, 2007, January 8).

Recently, Adi Putra Abdul Ghani (12) Perak-born child genius stated that he is feeling the stress as being entitled as a "wonderkid". He says that there are so many expectations, and it is a burden he has to carry (The Star, 2011, May 2). This stress related symptoms if left unrecognized and untreated may lead further depression and later on may develop into serious bipolar illness (Royal College of Psychiatrists, 2011). Students presenting with an episode of depression should be carefully assessed for the possibility of a primary bipolar illness.

\subsection{Eating Disorders}

Eating disorders such as obesity, anorexia nervosa and bulimia nervosa are widely recognised in the student population (Royal Psychiatrists of London, 2011). The high occurrence of these illnesses in higher socioeconomic groups and the peak age at onset in adolescence make undergraduate students particularly vulnerable (McClelland \& Crisp, 2001).

According National Obesity Observatory (2011), there is a bi-directional association between obesity and depression. Obesity may behaviourally affect one's mental health by influencing the individual to undergo a strict diet and involve in episodes of binge eating. Anorexia Nervosa is also a type of psychological eating disorder (NEDA, 2005 \& NCCMH, 2004). According to NEDA (2005), anorexia nervosa is a serious, potentially life-threatening eating disorder characterized by self-starvation and excessive weight loss. Between 5-20\% of individuals struggling with anorexia nervosa will die. Anorexia nervosa has one of the highest death rates of any mental health condition (NEDA, 2005).

On the other hand, bulimics tend to get themselves involved in episodes of binging and purging. According to DSM-IV-TR $®$ Diagnostic and Statistical Manual of Mental Disorders published by the American Psychiatric Association (1994), bulimia nervosa is considered as a psychological disorder because bulimics have excessive concern about their weight and bodies, binge - eating repeatedly and inappropriate use of laxatives, fasting, vomit or exercising to compensate eating. As effect of their action, bulimics often complain of fatigue, lethargy, or feeling bloated, and they may suffer constipation, abdominal pain and on occasions swelling of the hands and feet or irregular menstruation (NCCMH, 2004).

\subsection{Autism-Spectrum Disorders}

According to National Institute of Mental Health (NIMH, 2011), autism is a group of developmental brain disorders, collectively called autism spectrum disorder (ASD). The term "spectrum" refers to the wide range of symptoms, skills, and levels of impairment, or disability, that children with ASD can have. Some children are mildly impaired by their symptoms, but others are severely disabled.

ASD is diagnosed according to guidelines listed in the Diagnostic and Statistical Manual of Mental Disorders, Fourth Edition - Text Revision (DSM-IV-TR) by APA (1994). The manual currently defines five disorders (as cited in NIMH, 2011), sometimes called pervasive developmental disorders (PDDs), as ASD:

- Autistic disorder (classic autism)

- Asperger's disorder (Asperger sydrome)

- Pervasive developmental disorder not otherwise specified (PDD-NOS)

- Rett's disorder (Rett syndrome)

- Childhood disintegrative disorder (CDD).

Children with ASD who have not yet developed meaningful gestures or language may simply scream or grab or otherwise act out until they are taught better ways to express their needs. As these children grown up, they can become aware of their difficulty in understanding others 
and in being understood (NIMH, 2011). The leading symptoms can include depression, suicidality, anxiety and obsessive-compulsive features (Royal College of Psychiatrists, 2011).

\subsection{Alcohol}

A newspaper report in 2011 has revealed that Malaysia has been named by the World Health Organisation (WHO) as the world's 10th largest consumer of alcohol despite its small population and size. Deputy Women, Family and Community Development Minister Heng Seai Kie said the problem of alcohol consumption in the country is getting serious. Road Safety Council estimated that drinking and driving caused $30 \%$ of road accidents nationwide, with $38 \%$ of these resulting in fatalities (The Star, 2011, May 23). Does this mean that Malaysian students are part of the statistics?

A recent publication by Shamsul Azhar et. al. (2012) on psycho-behavioral factors contributing to truancy among Malay secondary schools students in Malaysia have showed no association between truancy and alcohol abuse. They found that religious status showed the perception that religion is important in life and students' involvement in religious activities has associations with risky behaviors', in this case alcohol consumption.

It is a different situation in UK whereby a report by Royal College of Psychiatrists (2011) stated that high levels of alcohol intake have been a traditional feature of student life in the UK and elsewhere. This report claimed that young people start to drink more heavily when they are free of the constraints of life in the family home. Alcohol dependence is a condition that usually occurs after many years of heavy alcohol use. The main problem in students is harmful or hazardous drinking. Newcastle's Road Safety Council estimated that drinking and driving caused $30 \%$ of road accidents nationwide, with $38 \%$ of these resulting in fatalities (Royal College of Psychiatrists, 2011).

\subsection{Drug Misuse}

The problem of illicit drug use has been a long standing problem in Malaysia. It is well recognized that drug misuse is associated with many social, economic and health problems, including mental health problems (Gill, $\mathrm{OH}$ and Pillai, 2010). A case study by Khidzir et. al (2009) have found that the number of the first year students who are readily involved in drugs misuse are 21 person while 9 others are considered as having substance dependent disorder (SDD).

Anxiety disorders have consistently been cited as the commonest type of psychiatric disorder in drug users (Gill, $\mathrm{OH}$ and Pillai, 2010). Use of stimulants was more common in senior undergraduates. Rabiner et. al (2010) found that just over 5\% of undergraduates began using ADHD or Attention Deficit Hyperactivity Disorder stimulants between the first and second years of university. The reason for use was, again, to improve attention and performance
(Royal College of Psychiatrists, 2011).

\section{Ways for Promoting Mental Health}

Previous researchers as Knitzer (1986) in a study has pointed out that at the stage of adolescence is important to ensure that their mental health is in stable condition. In addition, parents and schools can help students with mental health problems by providing adequate support to them.

\subsection{Global Concern on Mental Health}

According to WHO (2012), every year on 10th of October, The World Health Organization joins in celebrating the World Mental Health Day. The day is celebrated at the initiative of the World Federation of Mental Health and WHO supports this initiative through raising awareness on mental health issues using its strong relationships with the Ministries of health and civil society organizations across the globe. WHO also develops technical and communication material and provides technical assistance to the countries for advocacy campaigns around the World Mental Health Day.

Last year the theme for the day is "Depression: A Global Crisis". The topic was chosen because depression can affect anyone and it is one of the most widespread illnesses, often co-existing with other serious illnesses. According to WHO (2012), unipolar depressive disorders were ranked as the third leading cause of the global burden of disease in 2004 and will move into first place by 2030 (World Federation of Mental Health, 2012). An estimated 400 million people in the world suffer from depression and there are about 3,000 reported suicide deaths every day (The Star, 2012, October 10). According to Assoc. Prof. Dr. Andrew Mohanraj, psychiatry at Perdana University Johns Hopkins School of Medicine, Kuala Lumpur, these alarming figures are significant because the overwhelming majority of people who commit suicide are persons with mental illness, particularly depression. The degree of pain of a person with depression can be understood if one considers that many prefer death to their suffering. The figures mentioned here should be a wake-up call for us to address depression as a global issue. Thus, it seems relevant for depression to be chosen for this year's theme. Malaysia also celebrates the 2012 National Level Mental Health Day as a way in promoting mental health across the country (The Star, 2012, October 8 \& The Star, 2012, October 10).

\subsection{Government's Role}

As previously discussed, mental health problems especially stress-related, among Malaysians including school children are a matter of serious concern and need to be addressed urgently so that mental disorders such as psychosis, depression and suicides can be minimized. As the number of teenagers and youths suffering from mental health problems seems to be on the rise, the Mental Health Advisory Council recommended the Government to 
conduct a 6 month pilot test randomly selected in schools to identify and address the situation (The Star, 2011, January 19).

The pilot study has found that $17.1 \%$ had symptoms suggestive of severe anxiety disorders, 5.2\% had severe depression symptoms and $4.8 \%$ experienced severe stress (Ang, 2011). The move is among efforts to identify students facing stress and depression so that counseling can be given before more serious situations happen to them. Mental Health Advisory Council member Dr Omar Mihat said that the project will be introduced in schools nationwide by the end of the year once the ministry has overcome some problems identified in the pilot study (The Star, January 19). He added that selected teachers would be trained to translate the results of the tests and determine if students were suffering from problems and advise them on what they could do on their own to reduce stress or depression. But according to National Union of Teaching Profession (NUTP) secretary-general Lok Yim Pheng, careful implementation is needed as mental health issue remain sensitive issues in our society. Thus, involvement of students and parents is seemed important in order to ensure effectiveness of the program.

Other than that, Tan Sri Dr. Lee Lam Thye, a member of Mental Health Council as addressed a few ways in promoting good mental health in school. These include talks, exhibitions and quizzes that can be held as extracurricular activities involving Parents Teachers Association (PTA) and clubs. The use of social media among the youngsters is also emphasized, such as Facebook as one of a "scanning medium" of mental health problem through status postings. Apart from that, schools need to have more trained counselors to guide and help students handle stress. Ang (2011) urges the need to include mental health component in the school health services which currently focus on physical illness only. School health service could help the schools in promoting mental health and coping skills among the students as well as training the school health team and increasing the number of doctors in school health team. The issue of mental health among students must be addressed with a sense of urgency. If their problems are not treated with proper concern, the nation will be burdened with a generation suffering from serious mental health problems in an ever-increasing competitive global environment (The Star, February 11, 2011).

\subsection{NGOs Role in Promoting Mental Health}

According to Ang (2011), NGOs play a vital role as advocates in bringing mental health to the forefront. Examples of mental health NGOSs are MMHA, Minda Malaysia and Mental Health Foundation. Ang (2011) has listed a few criterion for NGOs in order to be effective in promoting mental health, such as:

-The need to be committed and passionate champions

-Strong leadership is needed to set the pace \& direction

-More public health professionals should be involved as mental health advocate.

The role of NGOs in promoting mental health will be discussed further by looking at MMHA as an example. All the information discussed here are obtain from MMHA's official website (http://www.mentalhealth.org.my). The Malaysian Mental Health Association (MMHA) was founded in 1967 and is a community based NGO operating solely on public donations and a small annual grant from the Department of Social Welfare. Among the objectives of the MMHA are to be a dynamic advocate for positive attitudes towards mental health, to plan and execute mental health programmes and provide rehabilitation services. Mental Health is a community responsibility as mental health disorders can affect anyone (MMHA, 2008).

MMHA runs a Day Care Centre, a Charity Shop Project, organises public forums on mental health issues, provides support for carers of the mentally ill, runs Family to Family Education groups, conducts a Depression Support group and advocates for the rights of the mentally ill. MMHA has introduced the illness management \& recovery, line dancing, singing, art painting, gardening, indoor and outdoor games, daily exercising, occasional outings for the clients under its rehabilitation programme.

The rehabilitation programme is opened to those who have been diagnosed with a mental illness and are currently being treated by a psychiatrist. It is run daily from Monday to Friday, from 9 am to $4 \mathrm{pm}$. A small monthly fee is collected to partially cover the costs of the programme, including lunch on Thursdays and Fridays. MMHA occasionally implement a new rehabilitation program since December 2007 which adapted from US as evidence based practice. The Illness Management and Recovery (IMR) Programme that takes around 6 months and a year to be completed was introduced. The session involves group discussion and sharing of experiences; reflections and workbook exercises. It consists of 10 modules covering the following areas:

1. Introduction to the concept of Recovery

2. Explaining common psychiatric disorders: schizophrenia, bipolar disorders, depression

3. Stress vulnerability model for illness causation

4. Building social support

5. Using medications effectively

6. Drug and alcohol abuse

7. Reducing relapses

8. Coping with stress

9. Coping with problems and persistent symptoms

10 . Getting your needs met in the mental health system

IMR is a psycho-social education programme aimed primarily at helping those who are mentally ill to recover and specifically at:

- helping clients to understand their mental condition

- teaching them methods to cope with distressing symptoms and stress

- teaching them to communicate and verbalize their problems

- $\quad$ teaching them to manage their emotions 
- teaching them to be compliant with their medications, and recognize and report relapsing symptoms

- teaching them to set goals for socialization, and return to work.

While undergoing the IMR programme, clients are reviewed by the visiting psychiatrist at least once in 6 months to chart their progress, and as and when necessary if they encounter problems that need professional help. In addition to activities conducted at the centre, clients are also taken for outings like visit to the zoo, the museum, and other interesting places. This is part of developing socializing skills, and helping them to gain confidence in dealing with the outside world.

\subsection{Family Support}

Person's immediate family also plays an important role in helping them maintain good mental health by getting their mental problems treated. The most common sign of a mental health problem is a sudden change in the behavior of a person, a jovial person might turn into an introvert, become short-tempered, start keeping or speaking to oneself, have a disrupted sleep pattern, lose their appetite, is unable to carry out daily activities or starts displaying suicidal tendencies.

In other words the mental health problem is not so apparent because the condition starts to deteriorate slowly. However, a proper diagnosis by an expert and the right therapy are a must. Parents whose children start displaying symptoms of a mental health problem, often go into a self denial mode fearing the social stigma associated with mental illness. As a result, children suffer in silence and are ignored by their family and the society they live in.

Apart from that, family engagement is also needed to ensure the effectiveness of the treatment and intervention participated by the patient. In order to aid in recovery, parents have to ensure all the prescribed medications are taken by the patients as being prescribed the doctors. In order to provide a deeper understanding on the illness and various skills to care for those having diagnosed as having mental health problems, parents as well as the other family members could seek information from the internet or join any programs conducted by their nearest Community Health Centre. One of the example is MMHA through their Family-to -Family Education Programme that serve to train family members on how to care for their love ones (MMHA, 2008).

\section{Conclusion}

Mental health is common and can affect anyone. Greater awareness about mental health and early diagnosis can help to save thelives of people suffering from mental healthrelated problems. Getting rid of the stigma and discrimination associated with mental health issues is the first step towards keeping mental health illnesses in check and helping those suffering from mental problems.
Government via Ministry of Health and Ministry of Education should work closely in order to implement mental health programs in the school. Consequently, it is vital that the school counsellors and teachers have the knowledge, attitude and skills to help these students cope with their emotions, handle and manage their stress level. This could further help to correct the misconception about mental health and social stigma as previously discussed. Engagement with the media is needed to provide deeper understanding about mental health problems. Collaboration between government agencies and NGOs are vital in providing mental health activities and programs for the needy.

\section{References}

[1] Academy of Royal Medical Colleges. (2009). No Health Without Mental Health. The Alert Summary Report. July 2009. Royal College of Psychiatrist : London.

[2] Adelman, H., \& Taylor, L. (2006). The current status of mental health in the schools: A policy and practice brief. Los Angeles: UCLA School Mental Health Project.

[3] ADHD Medication Use By College Students. Journal of Attention Disorders, Vol. 13, 640 - 648.

[4] American Counseling Association, American School Counseling Association, National Association of School Psychologists, \& School Social Work Association of America. (2006). Removing barriers and improving student outcomes: The importance of school-based mental health services. Retrived from http://www.nasponline.org/advocacy/briefinghandout0306.p df

[5] American Psychiatric Association (1994). Diagnostic and Statistical Manual for Mental Disorders, 4th ed. APA: Washington D.C.

[6] Andrews, B. \& Wilding, J. M. (2004). The relation of depression and anxiety to life-stress and achievement in students. British Journal of Psychology, 95 (4): 509 - 522.

[7] Ang, K.T. (2011, November 15). Malaysian Mental Health Association: Current Perspectives in Mental Health. $3^{\text {rd }}$ Asia Pacific Conference on Public Health, Grand Dorsett Subang Hotel.

[8] Cardwell, M \& Flanagan, C. (2005). Psychology AS The Good Companion. UK : Nelson Thornes.

[9] Eisenberg, D, Gollust, SE, Golberstein, E, Hefner, JL. (2007). Prevalence and Correlates of Depression, Anxiety and Suicidality among University Students. American Journal of Orthopsychiatry 77(4): 534-542.

[10] Gill, J.S, OH, K. and Pillai, S.K. (2010). Anxiety disorders among incarcerated drug users. Malaysian Journal of Psychiatry, Vol. 19, No. 1.

[11] Harding, $\mathrm{T}$ and Zimmerman, E. (1989). Psychiatric Symptoms, Cognitive Stress And Vulnerability Factors: A Study In Remand Prison. Br J Psychiatry,;155: 36-43.

[12] Kohrt, B., Jordans, M., Tol, W., Speckman, R., Maharjan, S., 
Worthman, C., \& Komproe, I. (2008). Comparison of Mental Health between Former Child Soldiers and Children Never Conscripted by Armed Groups in Nepal. Journal of American Medical Association (JAMA); 300(6):691-702.

[13] Kohrt, B.A. \& Maharjan, S.M. (2009). When a child is no longer a child: Understanding child soldiers within Nepali ethnopsychology of child development and violence. Studies in Nepali History and Society (SINHAS), 14(1), 107-142.

[14] Maharjan, S.M. (2010). World Mental Health Day. Retrieved from http://sujenman.wordpress.com/2010/10/10/world-mentalhealth-day/

[15] Malaysian Mental Health Association. (2008). About Us. Retrieved from http://mentalhealth.org.my/index.cfm?menuid=63\&parentid $=35$

[16] McClelland, L., \& Crisp, A. (2001) Anorexia nervosa and social class. International Journal of Eating Disorders, 29, 150-156.

[17] Md. Aris Safree Md Yasin\& Mariam Adawiah Dzulkifli. (2011). Differences in depression, anxiety and stress. Journal of Sustainability Science and Management Volume 6 Number 1, June 2011: 169-178.

[18] Mehanna, Z. \& Richa, S. (2006) Prevalence of anxiety and depressive disorders in medical students: transversal study in medical students in the Saint-Joseph University of Beirut. Encephale, 32(6 Pt 1), 976-982.

[19] MySinchew. (2012, August 9). Malaysians lack understanding of mental health issues.MySinchew.Com. Retrieved on December 7, 2012 from http://www.mysinchew.com/node/76396

[20] National Collaborating Centre for Mental Health (NCCMH). (2004). Core interventions in the treatment and management of anorexia nervosa, bulimia nervosa and related eating disorders.National Collaborating Centre for Mental Health. Royal College of Psychiatrists' Research Unit : London.

[21] National Eating Disorders Association (NEDA). (2005).Anorexia Nervosa. Retrieved from http://www.nationaleatingdisorders.org/nedaDir/files/docum ents/handouts/Anorexia.pdf

[22] National Institute of Mental Health (NIMH). (2011). A Parent's Guide to Autism Spectrum Disorder. U.S. Department of Health \& Human Services. Retrieved on 6 December, 2012 from http://www.nimh.nih.gov/health/publications/a-parentsguide-to-autism-spectrum-disorder/complete-index.shtml

[23] National Obesity Observatory (NOO). (2011). Obesity and mental health. Solution for Public Health. Retrieved from : http://www.noo.org.uk/uploads/doc/vid_10266_Obesity\%20 and\%20mental\%20healthFINAL_070311_MG.pdf

[24] President's New Freedom Commission on Mental Health. (2003). Achieving the promise: Transforming mental health care in America. Final report (DHHS Pub. No. SMA-033832). Rockville, MD: Department of Health and Human Services.

[25] Rabiner, D. L., Anastopoulos, A. D., Costello, E. J., Et Al (2010) Predictors of Nonmedical
[26] Royal College of Psychiatrists. (2011). Mental Health of Students in Higher Education : College Report of Students CR166 Royal College of Psychiatrists. Royal College of Psychiatrists : London.

[27] Seligman, L. D. \&Wuyek, L. A. (2007). Correlates of Separation Anxiety Symptoms Among First-Semester College Students: An Exploratory Study. The Journal of Psychology, 141 (2): 135 - 146.

[28] Skalski, A.K. And Smith, M.J (2006). Responding to the Mental Health Needs of Students. Students Services. PL September 2006. Retrived from:http://www.nasponline.org/resources/principals/School Based $\% 20$ Mental $\% 20$ Health\%20Services $\% 20$ NASSP $\% 20$ S ept\%202006.pdf

[29] Stevenson. W (2006). Multiple predictors of psychological well-being among urban African American adolescent. Proquest Education Journals Service. 41,162, 341, 2006.

[30] Teachers College, Columbia University. (2005). The social costs of inadequat education. Symposium conducted at Columbia University, NY.

[31] The Star. (2007, January 8). "Boy genius" dies. The Star Online. Retrieved on December 5, 2012 from http://thestar.com.my/news/story.asp?file=/2007/1/8/nation/ $16504922 \& \mathrm{sec}=$ nation

[32] The Star. (2011, February 11). Promote good mental health. The Star Online. Retrieved on December 5, 2012 from http://thestar.com.my/news/story.asp?file=/2011/2/11/focus/ $8041496 \&$ sec $=$ focus

[33] The Star. (2011, January 19). School pilot project to detect stress and depression among students. The Star Online. Retrieved on December 7, 2012.

[34] The Star. (2012, October 8). Mental health problems afflicting teens increasing.The Star Online. Retrieved on December 7, 2012

[35] The Sun Daily. (2012, February 16). 12\% Malaysians suffer from some forms of mental illness. Retrieved on December 8, 2012 from http://www.thesundaily.my/news/297933

[36] U.S. Department of Health and Human Services.(1999). Mental health: A report of the surgeon general. Executive summary. Rockville,MD:National Institute

[37] Wan, D. (2012). In World Federation of Mental Health (2012). Depression : A global crisis. World Mental Health Day Report. Retrieved on December 7, 2012 fromhttp://www.wfmh.org/2012DOCS/WMHDay\%202012 \%20SMALL\%20FILE\%20FINAL.pdf

[38] WHO (2012). Mental Health. Retrieved on November 29, 2012 fromhttp://www.who.int/topics/mental_health/en/

[39] World Federation of Mental Health (2012). Depression : A global crisis. World Mental Health Day Report.. Retrieved on December 7, 2012 fromhttp://www.wfmh.org/2012DOCS/WMHDay\%202012 \%20SMALL\%20FILE\%20FINAL.pdf

[40] Zaid, Z. A., Chan, S. C., \& Ho, J. J. (2007). Emotional disorders among medical students in a Malaysian private medical school. Singapore Medical Journal. 48 (10): 895 899 
[41] Zivin, K., Eisenberg, D., Gollust, S., Golberstein, E. (2009). Persistence of Mental Health Problems and Needs in a College Student Population. Journal of Affective Disorders 117(3): 180-185. 